\title{
Research on the Connotation Orientation and ESP Practice Mode of College English in the view of EDR
}

\author{
Hu Luping \\ Zaozhuang Vocational College of Science \& Technology, Tengzhou, 277599, China \\ E-mail: huluping820620@163.com
}

Keywords: EDR; College English; ESP; the practice mode

\begin{abstract}
Under the guidance of EDR theory, this paper investigates and analyzes the connotation orientation of college English, establishes its ESP teaching practice mode, and conducts three rounds of research and application. In the first round, the demand analysis, discipline status definition, connotation construction and the application feedback of college English courses are completed, and the overall design principles of ESP are summarized. Then, according to the application feedback in the first round, it modifies the overall design of ESP and conducts the second round research to get the feedback on its theoretical basis and application, finally summarizing the connotation orientation and the practice mode of ESP courses of college English in the new era.
\end{abstract}

\section{Introduction}

The curriculum study of college English is a breakthrough point to reform higher education and to cultivate talents. It is also a field where information technology is most likely to be applied to improve the traditional teaching mode.[1] With the forthcoming of College English Teaching Guide dominantly developed by the Education Ministry, a series of problems appear including how to reform college English teaching, determine its course nature, enhance its connotation, restructure teaching objectives and the curriculum system, and innovate the evaluation system in the new historical period. It is fair to say that under the background of national macro-control of higher education globalization, current researches on college English curriculum is of more strategic educational significance and of more academic and practical value.

\section{EDR-A New Methodology in Educational Research Field}

Education Design Research (EDR), also known as Design-based Research, is a formative research system based on "theme" and guided by "problem". The design method of loop iteration is adopted to solve several key complex problems in the field of educational research.[2] These problems are as follows: 1 . Theories about the nature of learning in various situations; 2 . Education phenomena and methods in real environment; 3. Theoretical and practical research results in formative assessment. It follows that EDR is a formative research process during which researchers, research subjects and other participants work together and comprehensively apply various methods to solve practical problems in real environment. [3] Based on practical feedback, researches are constantly improved for optimized results to make scientific and effective designs, which leads to the birth of a new paradigm that achieves common development of both theory and practice. Therefore, EDR is of great significance for promoting new educational theories, and for improving the relevance, effectiveness and applicability of the theoretical system in educational practice.

\section{Research Design}

\section{A. Research Framework}

According to the loop iteration of EDR, the present paper firstly makes a demand analysis and a comprehensive investigation of college English curriculums from multi-perspectives, and then 
conducts three rounds of iteration researches and practical illustration based on the previously focused problems. [4] Each round focuses on four aspects that include curriculum orientation and connotation construction, ESP courses design and development, theoretical practice, and summary. The next round of research revises the results in the previous round and produces new results. After three rounds of cycle iteration, the following four questions are summarized: 1 .How to define the discipline status of college English and construct its connotation; 2.What are the theoretical basis and design of ESP courses; 3. What is the practice mode of ESP courses. The first two questions focus on theoretical research while the third question emphasizes concrete operations linking theory with practice. These three questions are studied in sequence, thus jointly forming a research entity. As shown in Figure 1-1, the design is based on the phase cyclic research design integration frame theory of Brenda Banana-Ritland.

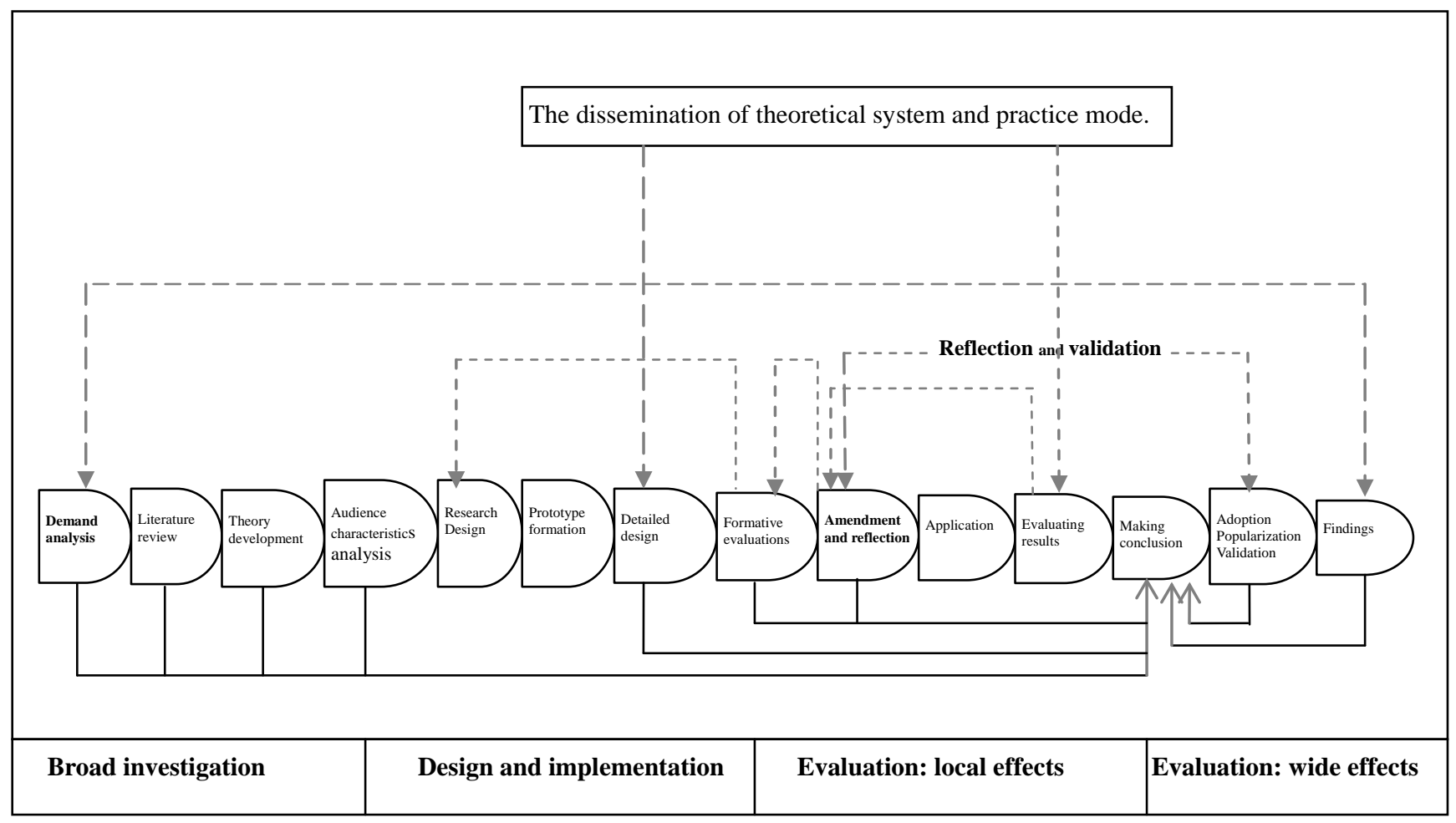

Figure 1-1

Firstly, comprehensive analysis and evaluation of the developments, goals and positioning of college English will be conducted through comprehensive investigations, literature surveys and reviews. Under the guidance of mixed learning theory and cognitive load theory, the current status of curriculum and the needs of audience will be analyzed and identified through class observation, questionnaires and interviews in a real experimental teaching environment and we will analyze and summarize the causes of the problems and their solutions; we will clarify the design goals and content orientation of College English in the current teaching process. Secondly, based on the education linguistics and ESP related theory, the design and development of college English ESP courses will be conducted again according to the providing specific strategy and principle. Then, we will group the subjects, determine the scope of the experiment and the subject's mastery of knowledge is measured by standardized tests (knowledge level); qualitative analysis of subjects' emotions and attitudes will be conducted by questionnaires and in-depth interviews, such as students' learning motivation, learning interest and self-learning ability(emotional and attitudinal level). Their comprehensive application ability (competence level) of language will be determined through practice and examination. Finally, we will revise and improve the every link of ESP theoretical system and practice model by analyzing and reflecting the development of the new model. We will develop and improve the design principles, theories and implementation plan of college English curriculum through the teaching practice and EDR experimental research designed as shown in Figure 1.2. 


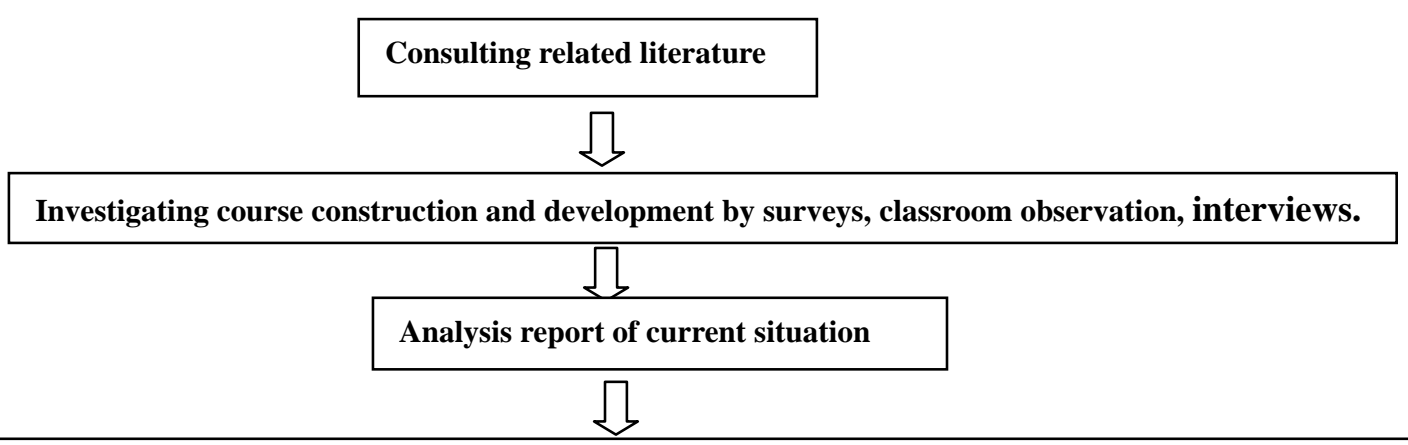

Identifying problems and solving strategies, formulating curriculum design goals and establishing connotation orientation

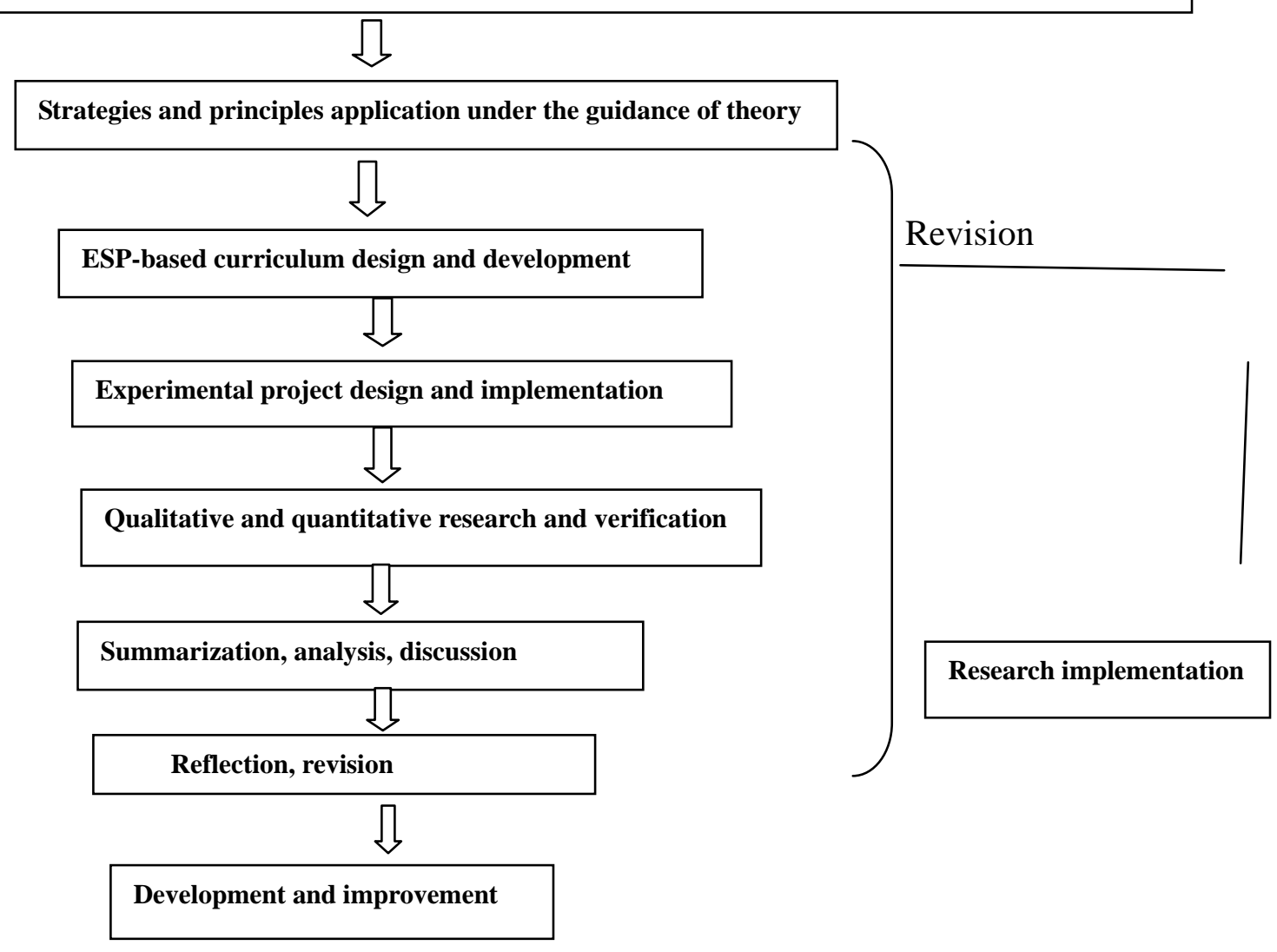

Figure 1.2

\section{B. Implementation and Circulation of Research}

We will revise the connotation of the generated college English curriculum and the initial planning of the ESP practice through the formative research evaluation, defect analysis and reflection method. We will mainly analyze the comparative study of the motivation and attitude of the students under the ESP practice model and study students' satisfaction with ESP's target demand and interaction between teachers and students in classroom. The research in this phase pays attention to the administrative support of the school to the experiment, and obtains follow-up support for the teachers and students to various degrees, including the improvement of the artificial intelligence teaching environment and the campus network digital resource teaching platform, the development and application of flipping the classroom, micro lessons, Mooc teaching platform and other teaching modes and means.

At the same time, we will construct a new evaluation system for college English courses, and carry out the evaluation of evaluation criteria for college English ESP teaching and the optimization of evaluation criteria. We will compare the monitoring and evaluation of the student's learning process by teachers with the students' self-evaluation and mutual evaluation as a way to gradually 
form a more reasonable theory and practice system, maximizing the incentive, guidance and quality control role of test and evaluation to the college English teaching. A real "teaching, learning, test" interaction will take shape.

Through numerous validation and iterative research, the complement and optimization of the theoretical system of college English courses has been formed, namely: the rationality, scientific orientation and connotation construction of College English ESP based on content; and the solution to the problem which is a new model of college English teaching practice based on ESP.

\section{Conclusion}

College English course, as the most common and most influential public courses, is a major feature of China's higher education in the field of foreign language education. This paper adopts EDR thriving in the field of international education research as a methodological guide, take the reform of the college English course teaching system as a case and study the connotation of university English curriculum and the practice mode of ESP. The research results include two levels: On the practical level, EDP teaching method is used to design the ESP teaching model and develop ESP-based curriculum system, teaching content, means and methods, and evaluation system development; on the theoretical level, by recording and analyzing the research process, the results and the changes that have taken place, the principle of college English course design based on ESP theory is constructed, which further clarifies the subject attributes of college English courses and strengthens their connotation and positioning development direction.

\section{References}

[1] Transformation and contextualisation: conceptualising students' conceptual understandings of threshold concepts in calculus[J] . Max Scheja,Kerstin Pettersson. Higher Education . 2010 (2)

[2] Students' perceptions of institutional practices: the case of limits of functions in college level Calculus courses[J] . Nadia Hardy. Educational Studies in Mathematics . 2009 (3)

[3] Educational Design Research. Jan van den Akker,„K.Gravemeijer,,N.Nieveen,S.McKenney. . 2006

[4] Design-based research and technology-enhanced learning environments[J] . Feng Wang,Michael J. Hannafin. Educational Technology Research and Development . 2005 (4)

[5] Design-based research:An emerging paradigm for educational inquiry. Design-Based Research Collective. Educational Research . 2003 